\title{
Original Article Portfolio insurance with a dynamic floor
}

Received (in revised form): 7th July 2009

\section{Huai-I Lee}

is an associate professor of finance in the Department of Finance at WuFeng University, Chiayi, Taiwan. He received his $\mathrm{PhD}$ degree (major in business administration) from National Cheng Kung University, Taiwan. His research interests are in the fields of futures and options, asset allocation, portfolio insurance and financial management.

\section{Hsinan Hsu}

is a professor of finance in the Department of Finance at Feng Chia University, Taichung, Taiwan. Before the present job, he had taught at several universities, including National Cheng Kung University, Tainan, Taiwan. He received his MBA degree from Cheng-Chi University, Taipei, Taiwan, and PhD degree (major in finance) from Lehigh University, United States. His research interests have been in futures and options, investments, asset management, portfolio insurance, pricing in imperfect markets and financial management. He has published more than 70 articles in journals.

\section{Min-Hsien Chiang}

is a professor at the Institute of International Business, National Cheng Kung University, Taiwan. He received his PhD from Syracuse University, New York, United States. His research interests include market microstructure, financial econometrics, investment finance, corporate finance, non-stationary time series and non-stationary panels.

Correspondence: Huai-I Lee, Department of Finance, WuFeng University, 117, Chian-Kuo Road Sec. 2, Ming-Hsiung, Chia-yi, 621, Taiwan, R.O.C.

ABSTRACT Within the classic floor discipline of portfolio insurance, there exists a trade-off between upside capture and downside protection. However, portfolio insurance with a dynamic floor could improve the effectiveness of asset management. The dynamic floor principle states that when the stock price rises, investors freeze the floor and when the stock price decreases, investors increase the floor. On the basis of this principle, we propose the equal amount dynamic floor (EADF) discipline. Results from simulation and sensitivity analysis show that the EADF discipline outperforms the fixed floor discipline in both better downside protection and Sharpe ratios generation in the long run.

Journal of Derivatives \& Hedge Funds (2010) 16, 219-230. doi:10.1057/jdhf.2010.16

Keywords: portfolio insurance; equal amount dynamic floor discipline; asset management; constant proportion portfolio insurance; portfolio management; downside protection 


\section{INTRODUCTION}

Clark and Arnott ${ }^{1}$ state that a trade-off exists between upside capture and downside protection for portfolio insurance that restricts its performance. Aliprantis ${ }^{2}$ demonstrates that if the derivative markets are complete, a minimumcost portfolio insurance strategy enables investors to avoid losses while still capturing the upside potential of a portfolio. Assuming a complete derivative markets, this suggestion reduces the practical application of portfolio insurance. Alternatively, in an effort to overcome this limitation, Rattiner ${ }^{3}$ suggests that, as a result of the cash settlement feature, the use of index options as trading assets could improve this performance by lowering transaction costs and reducing the unnecessary transactions that result from dynamic portfolio insurance strategies. However, trading index options restricts the general application of portfolio insurance. In contrast to these two proposals, we recommend improving the effectiveness of portfolio insurance by changing the floor discipline from constant to dynamic.

We explore the mechanisms of current dynamic portfolio insurance strategies, such as synthetic put (SP) and constant proportion portfolio insurance (CPPI), to find whether investors are able to improve their asset management performance by simply changing the floor discipline from a fixed floor to a dynamic floor rule. With the implication, enforcing the downside protection will result in an increase of utility, of loss-aversion, we propose an equal amount dynamic floor (EADF) as an alternative to a fixed floor discipline.

Using simulation evidence, we demonstrate that the EADF discipline outperforms the fixed floor discipline without increasing the complexity of portfolio insurance. We find the
EADF discipline to be manageable in practice and the sensitivity analysis results to be consistent with the simulation results to support the robustness of the EADF as a floor discipline for asset management.

We show that the dynamic floor discipline is capable of creating ladder return distributions that enable investors to get rid of loss in the long run. Moreover, the ladder downside protection mechanism limits the return distribution to result in smaller standard deviations. As a result, the EADF reduces uncertainty to create higher risk-adjusted returns. We also show that the suggested type of dynamic floor discipline is practical and manageable, given that the model of dynamic insurance strategies remains unchanged.

This article is organized as follows: the next section explores the floor principle of dynamic portfolio insurance. The subsequent section reports the results of 1500 simulations we conduct to illustrate the properties of the proposed floor discipline and a sensitivity analysis of parameters to ensure those properties demonstrated in the simulation are robust. The last section concludes.

\section{THE FLOOR PRINCIPLE OF DYNAMIC PORTFOLIO INSURANCE}

The main strategies of dynamic portfolio insurance are CPPI and SP. These strategies, with dynamic floor discipline, are discussed subsequently.

\section{The floor discipline of the CPPI strategy}

For a portfolio with value $A_{0}$ at time $t=0$, a fixed proportion of the portfolio, $F_{0}$, is set as a 
floor. A floor must be set in advance by definition of the fixed floor discipline. Once the floor has been set, it cannot be changed. The difference between the value of the portfolio and the fixed floor is the cushion, $U_{0}$. By definition of the CPPI strategy, the initial value of a risky asset is a multiple of the cushion, that is, $E_{0}=m \times U_{0}$, where $E_{0}$ is the initial value of the risky asset and $m$ is the multiple. The multiple must be greater than one, is set by investors in advance and cannot be changed after it has been set.

For example, if the risky asset is stock, then the initial value of the risky asset is equal to the stock price at time $t=0$ multiplied by the number of shares at $t=0$. The total assets are the sum of the risky asset and the safe asset (cash) that will be invested in, for example, treasury bills and held until the next rebalance.

Thus, the value of total assets is $A_{0}=S_{0} \times n_{0}+B_{0}$, where $S_{0}$ is the stock price at $t=0, n_{0}$ is the number of shares at $t=0$ and $B_{0}$ is the safe asset at $t=0$. Differentiating the value of total assets with respect to the stock price yields $\partial A / \partial S=n_{0}$. Thus, the relationship between changes in the value of the total assets and changes in the stock price shows that the instantaneous rate of change in the value of the total assets to changes in the stock price is the initial holding shares.

The main purpose of portfolio insurance is to provide upside capture and downside protection. Prospect theory suggests that pursuing downside protection is more important than chasing upside capture. To achieve the goal of a better downside protection, the number of shares must decrease as the stock price goes down. As the stock price goes down, the value of the total assets will decrease more slowly than the stock price if the shares held decrease. However, the value of the total assets will decrease proportionally to the stock price if the holding shares remain unchanged. Worse, the value of the total assets will decrease more rapidly than the stock price if the amount of shares held increase.

The source of the changes in holding shares can be determined by noting that the initial value of the risky asset, which is the stock price multiplied by the number of shares at $t=0$, is equal to the multiple multiplied by the difference between the initial value of the portfolio and the floor. Given the multiple to be constant, the total differential of the initial value of the stock illustrates that changes in the holding shares are composed of changes in the assets' value, changes in the floor and changes in the stock price (see Appendix).

Although the classical fixed floor discipline simplifies the model, this discipline sacrifices the function of the floor, which may reduce the effectiveness of the CPPI strategy. The changes in the floor are negative. Thus, to achieve the purpose of a better downside protection, the floor must increase when the stock price goes down. This results in a decrease in the number of holding shares to increase downside protection.

\section{The floor discipline of the SP strategy}

The protective put strategy (that is, buy a put option and buy a underlying stock) can be fully transformed into an SP strategy, such that the asset allocation at $t=0$ is the sum of the value of the risky asset that will be invested in $n_{0} N\left(d_{1}\right)_{0}$ shares of stock and the value of the safe asset that will be invested in treasury bills.

The asset allocation of the SP strategy is similar to the CPPI strategy. Both have the same 
mechanism of upside capture and downside protection for the portfolio. Therefore, the holding shares have to decrease when the stock price goes down. The change in holding shares is derived from changes in the value of total assets, changes in the value of the discount rate, changes in the floor, changes in the self-financial factor and changes in the stock price (see Appendix).

Similar to the fixed floor discipline with a constant floor, this discipline sacrifices efficiency for simplicity. Thus, to satisfy the purpose of a better downside protection, the floor has to increase when the stock price goes down.

\section{The EADF discipline for the CPPI and SP strategies}

The floor discipline of the CPPI and SP strategies demonstrate that a dynamic floor discipline better fulfills the purpose of portfolio insurance. Thus, we propose the EADF discipline for the CPPI and SP strategies.

The assumptions of risk aversion or loss aversion motivate the current strategies of portfolio choices. Leland ${ }^{4}$ argued that a market portfolio is mean-variance inefficient.

Consequently, there are ways to achieve a higher Sharpe ratio that do not require superior information to implement, as demonstrated by an investor improving a portfolio's performance by 'selling' skewness. Among others, Basak and Shapiro ${ }^{5}$ derive the wealth profile of a constant relative risk aversion investor constrained by a value-at-risk. Berkelaar et al ${ }^{6}$ apply loss aversion to explore the optimal portfolio choice. Both studies obtain return distributions similar to those created by portfolio insurance. Thus, we apply prospect theory as the guide theory for floor discipline design. Prospect theory was first introduced by Kahneman and Tversky. ${ }^{7}$ The studies that follow separate the utility function into a value function and a weighting function to explore mental and behavioral aspects of an agent conducting a prospect. The value function consists of two different slopes of utility. One models changes of utility in a scenario of gain, and the other depicts changes in utility in a scenario of loss. This contingent property illustrates that investors suffer a greater loss of utility from a one unit decrease in wealth than the gain of utility from a one unit increase in wealth. This implies that enforcing the downside protection will result in an increase of utility.

In practice, Black and Perold ${ }^{8}$ show that the CPPI strategy suffers a huge reversal cost when the stock prices reverse after a significant increase in price. This implies that enforcing upside capture does not necessarily create better upside capture.

Hence, both prospect theory and observed practice suggest that increasing the floor in the scenario where the stock price moves down, and keeping the floor discipline unchanged in the scenario where the stock price goes up, could create better utility satisfaction.

For changes in stock price that are cumulatively equal to $\alpha$ per cent (for example, 5 per cent), the original floor $\left(F_{0}\right)$ is renewed as the following rule: Let $F_{1}=F_{0}$ if the stock price goes up by $\alpha$ per cent; otherwise, $F_{1}=F_{0}+\gamma$, if the stock price goes down by $\alpha$ per cent, where $F_{0}$ is the original floor, $\gamma(>0)$ is the fixed amount to be adjusted, and $F_{1}$ is the new floor.

Treating the fixed floor disciplines of the CPPI and SP strategies as benchmarks, both of the EADF disciplines of the CPPI and SP strategies can hold less shares when the stock price goes down. Thus, the EADF disciplines 
can achieve a better downside protection than the fixed floor discipline (see Appendix).

\section{SIMULATION AND SENSITIVITY ANALYSIS OF PARAMETERS}

\section{Simulation results}

Many previous studies have used simulation as a method to examine portfolio insurance strategies. ${ }^{9-12}$ In this section, we perform simulation to investigate the difference between the fixed floor discipline and the EADF discipline.

The Sharpe ratio is a widely acceptable criterion to judge asset management performances. As the riskless interest rate varies depending on changes in the economy, instead of the Sharpe ratio we apply the mean to the standard deviation ratio as a representative measure of the Sharpe ratio (see Bansal et al ${ }^{13}$ for more on the use of the mean to standard deviation ratio). Hence, treating the fixed floor discipline of chosen strategies as benchmarks, we compare the mean to standard deviation ratio between these two floor disciplines using simulations.

We follow the stock price simulation technique proposed by Boyle, ${ }^{14}$ which assumes that stock prices follow a geometric Brownian motion. The parameters are set as follows: the annual riskless interest rate is 4 per cent, the volatility of the stock prices is 0.2 , the initial stock price is US $\$ 100$ and the number of annual trading days is 255 . The multiple of the CPPI strategy is 1.5 . The initial funds for investment are $\$ 10000$ and the initial floor is 80 per cent of the initial capital. For the SP strategy, the initial stock price is $\$ 100$, the exercise price is $\$ 85$, the volatility is 0.2 per annum and the annual riskless interest rate is 4 per cent. The investment horizon is 1 year. The number of shares is rebalanced based on the market move discipline, which is set at 5 per cent. The amount of floor adjustment is $\$ 50$.

Each estimate of the return of portfolio insurance is obtained using 1500 trials, where each trial corresponds to a possible stock path. The statistics of various strategies of the simulation are reported in Table 1. Panel A of Table 1 presents statistics between the two floor disciplines of the SP strategy. Compared to the truncated return distributions created by a fixed floor discipline, the confidence intervals of the EADF discipline demonstrate that the proposed discipline forms a ladder return distribution gradually. This benefits investors by getting rid of loss. The EADF discipline also creates smaller standard deviations to result in higher mean to standard deviation ratios. Ladder relative ratios of mean to standard deviation ratio illustrate that the EADF gradually outperforms the fixed floor discipline in the SP strategy. Panel B of Table 1 reports the simulation results of the EADF and fixed floor disciplines of the CPPI strategy. Panel B illustrates similar information to that of Panel A. That is, compared to the fixed floor discipline, the EADF creates a ladder return distribution gradually and creates smaller standard deviations to form relatively higher Sharpe ratios. As a result, ladder relative ratios of mean to standard deviations ratio indicate that the EADF outperforms the fixed floor discipline in the long run.

\section{Sensitivity analysis for parameters}

We analyze the sensitivity of the performance against changes in return volatility $(\sigma)$ and riskless interest rate $(r)$. Different markets usually 


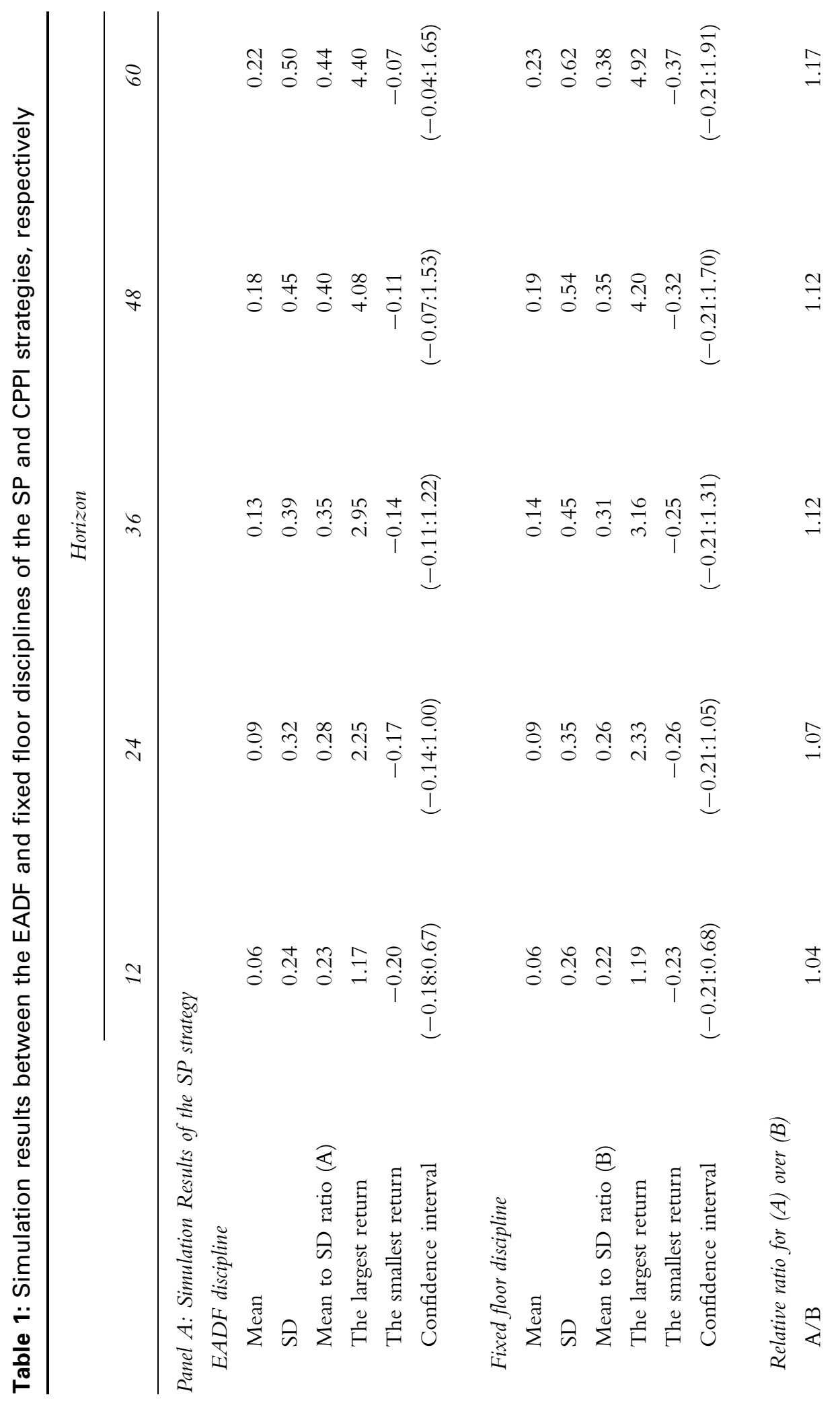




\section{Portfolio insurance with a dynamic floor 凉.}

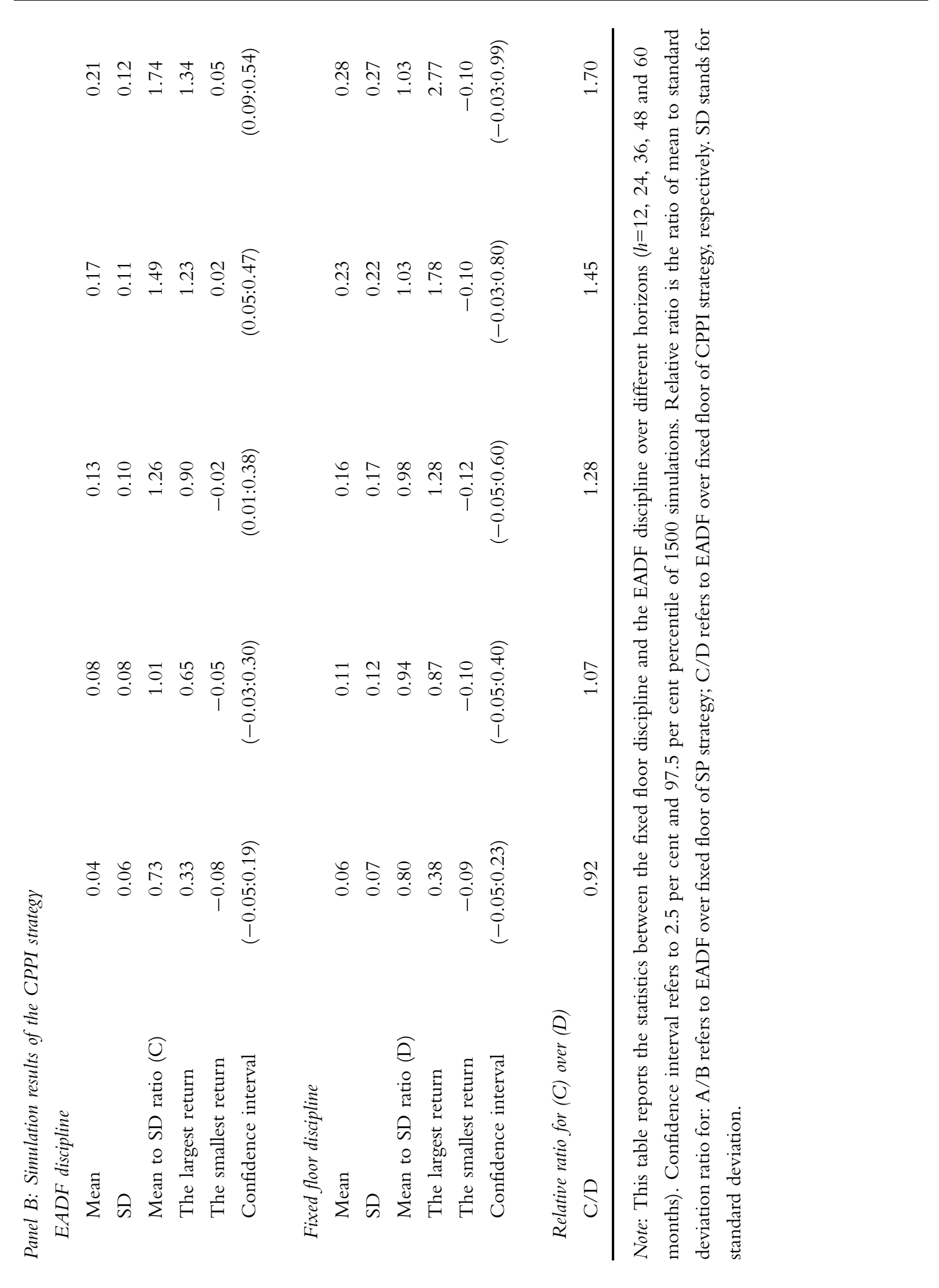


demonstrate different volatilities, and the riskless interest rates are set by the Fed (or central banks), which usually correspond to changes of economy. These sensitivity analyses are designed to explore the properties of the EADF under scenarios of changes to the market and economy. Thus, Ceteris paribus, we perform sensitivity analysis with return volatilities to be 15 per cent

Table 2: Sensitivity analysis of parameters for the SP and CPPI strategies between the EADF and fixed floor disciplines

\begin{tabular}{|c|c|c|c|c|c|c|c|c|c|c|}
\hline \multirow[t]{3}{*}{ Horizon } & \multicolumn{4}{|c|}{ SP strategy } & \multirow[t]{3}{*}{$A / B$} & \multicolumn{4}{|c|}{ CPPI strategy } & \multirow[t]{3}{*}{$C / D$} \\
\hline & \multicolumn{2}{|r|}{$E A D F$} & \multicolumn{2}{|c|}{ Fixed floor } & & \multicolumn{2}{|r|}{$E A D F$} & \multicolumn{2}{|c|}{ Fixed floor } & \\
\hline & $\begin{array}{c}S \text { ratio } \\
(A)\end{array}$ & $\begin{array}{c}\text { Confidence } \\
\text { interval }\end{array}$ & $\begin{array}{l}S \text { ratio } \\
\text { (B) }\end{array}$ & $\begin{array}{c}\text { Confidence } \\
\text { interval }\end{array}$ & & $\begin{array}{l}S \text { ratio } \\
(C)\end{array}$ & $\begin{array}{c}\text { Confidence } \\
\text { interval }\end{array}$ & $\begin{array}{l}S \text { ratio } \\
(D)\end{array}$ & $\begin{array}{c}\text { Confidence } \\
\text { interval }\end{array}$ & \\
\hline \multicolumn{11}{|c|}{$r=4 \%, \sigma=15 \%$} \\
\hline 12 & 0.28 & $(-0.18: 0.50)$ & 0.27 & $(-0.21: 0.51)$ & 1.02 & 0.98 & $(-0.03: 0.15)$ & 1.08 & $(-0.03: 0.18)$ & 0.91 \\
\hline 24 & 0.36 & $(-0.14: 0.76)$ & 0.35 & $(-0.20: 0.77)$ & 1.04 & 1.39 & (0.00:0.23) & 1.30 & $(-0.02: 0.31)$ & 1.07 \\
\hline 36 & 0.44 & $(-0.11: 0.94)$ & 0.39 & $(-0.21: 1.00)$ & 1.11 & 1.75 & (0.03:0.31) & 1.36 & $(-0.01: 0.47)$ & 1.29 \\
\hline 48 & 0.50 & $(-0.08: 1.16)$ & 0.45 & $(-0.21: 1.29)$ & 1.11 & 2.11 & $(0.07: 0.38)$ & 1.42 & (0.01:0.63) & 1.49 \\
\hline 60 & 0.56 & $(-0.04: 1.32)$ & 0.48 & $(-0.21: 1.46)$ & 1.16 & 2.51 & $(0.11: 0.43)$ & 1.45 & (0.03:0.74) & 1.73 \\
\hline \multicolumn{11}{|c|}{$r=4 \%, \sigma=25 \%$} \\
\hline 12 & 0.19 & $(-0.18: 0.81)$ & 0.18 & $(-0.21: 0.84)$ & 1.06 & 0.58 & $(-0.06: 0.23)$ & 0.63 & $(-0.07: 0.28)$ & 0.92 \\
\hline 24 & 0.24 & $(-0.14: 1.20)$ & 0.21 & $(-0.21: 1.28)$ & 1.14 & 0.79 & $(-0.04: 0.36)$ & 0.74 & $(-0.08: 0.48)$ & 1.07 \\
\hline 36 & 0.29 & $(-0.11: 1.49)$ & 0.24 & $(-0.21: 1.68)$ & 1.21 & 0.96 & $(0.00: 0.49)$ & 0.75 & $(-0.08: 0.77)$ & 1.27 \\
\hline 48 & 0.33 & $(-0.07: 1.77)$ & 0.27 & $(-0.21: 2.06)$ & 1.20 & 1.12 & $(0.03: 0.57)$ & 0.79 & $(-0.07: 0.97)$ & 1.42 \\
\hline 60 & 0.37 & $(-0.04: 1.92)$ & 0.29 & $(-0.21: 2.37)$ & 1.27 & 1.27 & $(0.08: 0.61)$ & 0.76 & $(-0.06: 1.20)$ & 1.66 \\
\hline \multicolumn{11}{|c|}{$r=2 \%, \sigma=20 \%$} \\
\hline 12 & 0.13 & $(-0.19: 0.63)$ & 0.13 & $(-0.21: 065)$ & 1.05 & 0.40 & $(-0.06: 016)$ & 0.70 & $(-0.06: 021)$ & 0.57 \\
\hline 24 & 0.15 & $(-0.17: 0.89)$ & 0.14 & $(-0.21: 0.94)$ & 1.11 & 0.57 & $(-0.05: 023)$ & 0.85 & $(-0.06: 036)$ & 0.67 \\
\hline 36 & 0.18 & $(-0.15: 1.07)$ & 0.15 & $(-0.21: 1.15)$ & 1.18 & 0.75 & $(-0.04: 0.27)$ & 0.90 & $(-0.06: 053)$ & 0.83 \\
\hline 48 & 0.21 & $(-0.14: 1.29)$ & 0.18 & $(-0.21: 1.43)$ & 1.17 & 0.92 & $(-0.02: 0.31)$ & 0.95 & $(-0.04: 0.66)$ & 0.97 \\
\hline 60 & 0.23 & $(-0.12: 1.39)$ & 0.19 & $(-0.21: 1.60)$ & 1.22 & 1.13 & (0.00:0.34) & 0.97 & $(-0.04: 0.81)$ & 1.17 \\
\hline \multicolumn{11}{|c|}{$r=6 \%, \sigma=20 \%$} \\
\hline 12 & 0.31 & $(-0.17: 0.69)$ & 0.30 & $(-0.21: 0.70)$ & 1.06 & 1.02 & $(-0.03: 0.22)$ & 0.88 & $(-0.05: 0.24)$ & 1.16 \\
\hline 24 & 0.41 & $(-0.12: 1.06)$ & 0.38 & $(-0.21: 1.11)$ & 1.07 & 1.37 & (0.00:0.36) & 1.03 & $(-0.05: 0.43)$ & 1.33 \\
\hline 36 & 0.49 & $(-0.07: 1.36)$ & 0.43 & $(-0.21: 1.49)$ & 1.13 & 1.61 & $(0.06: 0.51)$ & 1.06 & $(-0.04: 0.66)$ & 1.52 \\
\hline 48 & 0.56 & $(-0.01: 1.70)$ & 0.48 & $(-0.21: 1.87)$ & 1.16 & 1.83 & $(0.11: 0.64)$ & 1.09 & $(-0.02: 0.89)$ & 1.67 \\
\hline 60 & 0.63 & $(0.05: 1.92)$ & 0.52 & $(-0.21: 2.28)$ & 1.21 & 2.06 & (0.18:0.76) & 1.09 & $(-0.01: 1.11)$ & 1.88 \\
\hline
\end{tabular}

Note: This table reports the statistics between the fixed floor discipline and the EADF discipline over different horizons ( $h=12,24,36,48$ and 60 months). Confidence interval refers to 2.5 per cent and 97.5 per cent percentile of 1500 simulations. The technique of stock price simulation proposed by Boyle (1977) is applied to these sensitivity analyses. $S$ ratio stands for mean to standard deviation ratio. 
and 25 per cent, respectively, which should capture the performance of most of the mature and immerging markets. Meanwhile, Ceteris paribus, we conduct sensitivity analysis with riskless interest rates to be 2 per cent and 6 per cent, respectively, which cover most of the fluctuations of economy in the past decades and allow us to explore the performances in most of the economies. This method of using volatility and riskless interest rate for sensitivity analysis of parameters has been used in other studies, including Tannous and Lee-Sing. ${ }^{15}$

Table 2 presents the mean to standard deviation ratios and confidence intervals of various floor disciplines of chosen strategies under different parameter scenarios. Table 2 illustrates similar information to that of Table 1. That is, the return properties, such as forming ladder return distributions and higher Sharpe ratios in the long run, created by the EADF discipline do not change along with respect to changes in the parameters. Hence, the sensitivity analysis results are consistent with the simulation results to support that the EADF is a robust floor discipline for portfolio insurance.

\section{CONCLUSION}

The fixed floor discipline, which requires the floor to be constant, sacrifices the role of the floor in the context of up-trend markets and down-trend markets, and hence reduces the upside capture and downside protection. Prospect theory suggests that pursuing downside protection is more important than chasing upside capture. To achieve the goal of a better downside protection, the number of shares must decrease as the stock price goes down. The floor principle states that when the stock price goes down, the floor increases accordingly. A floor with this discipline could result in better portfolio insurance performance. On the basis of this principle, the EADF discipline is recommended.

Compared with the fixed floor discipline, simulation and sensitivity analysis evidence support the claim that the EADF discipline works better in both better downside protection and Sharpe ratio generation in the long run. Accordingly, future studies should explore the function of the multiple, which is defined as a constant, of CPPI strategy. This study also suggests forming a dynamic multiple discipline; thus, the knowledge of multiple in the CPPI will enrich the knowledge of dynamic portfolio insurance.

\section{REFERENCES}

1 Clarke, R.G. and Arnott, R.D. (1987) The cost of portfolio insurance: Tradeoffs and choices. Financial Analysts Journal 43: 35-47.

2 Aliprantis, C.D. (2000) Minimum-cost portfolio insurance. Journal of Economic Dynamics \& Control 24: 1703-1719.

3 Rattiner, J.H. (2001) Portfolio insurance: Index option strategies can improve returns and minimize risk in a down or turbulent market. Financial Planning 32: 171-174.

4 Leland, H.E. (1999) Beyond mean-variance: Performance measurement in a nonsymmetrical world. Financial Analysts Journal 55: 27-36.

5 Basak, S. and Shapiro, A. (2001) Value-at-risk based risk management: Optimal policies and asset prices. Review of Financial Studies 14: 371-405.

6 Berkelaar, A.B., Kouwenberg, R. and Post, T. (2004) Optimal portfolio choice under loss aversion. The Review of Economics and Statistics 86: 973-987.

7 Kahneman, D. and Tversky, A. (1979) Prospect theory: An analysis of decision under risk. Econometrica 47: 263-291.

8 Black, F. and Perold, A.F. (1992) Theory of constant proportion portfolio insurance. Journal of Economic Dynamics and Control 16: 403-426.

9 Brooks, R. (1989) Investment decision making with derivative securities. The Financial Review 24: 511-528. 
10 Chidambaran, N. and Figlewski, S. (1995) Streamlining Monte Carlo simulation with quasi-analytic method: Analysis of path-depend option strategy. The Journal of Derivatives 10: 29-51.

11 Tian, Y. (1995) Optimal bond trading with tax clienteles: A discrete-time dynamic trading model. The Financial Review 31: 313-341.

12 Robinson, B.L. (1998) The inefficiency costs of guaranteed investment products. The Journal of Derivatives 6: 25-36.

13 Bansal, R., Dahlquist, M. and Harvey, C.R. (2004) Dynamic Trading Strategies and Portfolio Choice. National Bureau of Economic Research, Inc., NBER Unpublished Working Paper: 10820.

14 Boyle, P.P. (1977) Options: A Monte Carlo approach. Journal of Financial Economics 4: 323-338.

15 Tannous, G.F. and Lee-Sing, C. (2008) Expected time value decay of options: Implications for put-rolling strategies. The Financial Review 43: 191-218.

\section{APPENDIX}

\section{Source of the changes in holding shares of CPPI}

Consider a portfolio with initial value $A_{0}$ at time $t=0$. A fixed proportion of the portfolio, $F_{0}$, is set as the floor, and the remainder is the cushion, $U_{0}$. That is,

$$
A_{0}=U_{0}+F_{0} .
$$

Assuming that a portfolio consists a risky asset and a safe asset, thus the total value of the portfolio at $t=0$ is the sum of the risky asset $\left(E_{0}\right)$ and the safe asset $\left(B_{0}\right)$,

$$
A_{0}=E_{0}+B_{0} .
$$

where $B_{0}=A_{0}-E_{0}$ is cash (a safe asset) that will be invested in treasury bills. By definition of the CPPI strategy, the relationship between $E_{0}$ and $U_{0}$ is

$$
E_{0}=m \times U_{0},
$$

where $m$ is the multiple. Assuming that the risky asset is a stock, we have

$$
E_{0}=S_{0} \times n_{0}
$$

where $S_{0}$ is the stock price at $t=0$, and $n_{0}$ is the number of shares at $t=0$. As known,

$E_{0}=m \times U_{0}, E_{0}=S_{0} n_{0}$, and $U_{0}=A_{0}-F_{0}$, we

have $S_{0} n_{0}=m A_{0}-m F_{0}$.

As the multiple is a constant $(d m=0)$, the total differential of the initial value of the stock $\left(d n=\left(m d A-m d F-n_{0} d S\right) / S_{0}\right)$ illustrates that changes in the holding shares $(d n)$ are composed of changes in the assets' value $(d A)$, changes in the floor $(d F)$ and changes in the stock price $(d S)$.

\section{Source of the changes in holding shares of the synthetic put (SP)}

According to the put-call parity, $S+P=C+X e^{-r T}$ where the right-hand side is the fiduciary call and the left-hand side is the protective put, whenever the floor $\left(F_{T}\right)$ is set, investors can invest the remainder in call options. Discounting the future value of the safe asset $\left(F_{T}\right)$ back to the initial value, the asset allocation at $t=0$ is the sum of the risky asset of the EFC strategy to be invested in $n_{0}$ units of call options and the safe asset that will be invested in treasury bills. That is,

$$
\begin{aligned}
A_{0} & =U_{0}+F_{T} \\
& =\left(U_{0}+F_{T}-F_{T} e^{-r T}\right)+F_{T} e^{-r T} \\
& =E_{0}^{E}+B_{0}^{E}
\end{aligned}
$$

where $E_{0}^{E}=\left(U_{0}+F_{T}-F_{T} e^{-r T}\right)$ is the sum of risky asset of the EFC strategy to be invested in $n_{0}$ units of call option, that is, $E_{0}^{E}=n_{0} C_{0}$, and $B_{0}^{E}=F_{T} e^{-r T}$ is the safe asset that will be invested in treasury bills. Substituting the price of the call option into the equation for the risky asset of the EFC strategy to be invested in $n_{0}$ units of call option yields

$$
\begin{aligned}
U_{0}+ & F_{T}-F_{T} e^{-r T}=n_{0} C_{0} \\
& =n_{0}\left[S_{0} N\left(d_{1}\right)_{0}-X e^{-r T} N\left(d_{2}\right)_{0}\right] \\
& \Rightarrow U_{0}+F_{T}-F_{T} e^{-r T}+n_{0} X e^{-r T} N\left(d_{2}\right)_{0} \\
& =n_{0} N\left(d_{1}\right)_{0} S_{0}
\end{aligned}
$$


Meanwhile,

$$
\begin{aligned}
A_{0}= & {\left[U_{0}+F_{T}-F_{T} e^{-r T}+n_{0} \cdot X \cdot e^{-r T} \cdot N\left(d_{2}\right)_{0}\right] } \\
& +\left[F_{T} e^{-r T}-n_{0} \cdot X \cdot e^{-r T} \cdot N\left(d_{2}\right)_{0}\right] \\
= & {\left[n_{0} S_{0} N\left(d_{1}\right)_{0}\right]+\left[F_{T} e^{-r T}-n_{0} X e^{-r T} N\left(d_{2}\right)_{0}\right] } \\
= & E_{0}^{S}+B_{0}^{S}
\end{aligned}
$$

where $X$ is the exercise price, $N($.$) is the$ cumulative probability of normal distribution,

$E_{0}^{S}=n_{0} S_{0} N\left(d_{1}\right)_{0}$ is the value of risky assets of the SP strategy that will be invested in $n_{0} N\left(d_{1}\right)_{0}$ shares of stock, and $B_{0}^{S}=F_{T} e^{-r T}-n_{0} X e^{-r T} N\left(d_{2}\right)_{0}$ is the value of safe assets that will be invested in treasury bills.

Substituting $n^{\prime}{ }_{0}=n_{0} N\left(d_{1}\right)_{0}$ and $Z_{0}=n_{0} X e^{-r T}$ $\times N\left(d_{2}\right)_{0}$, a self-financial factor into equation (A7) and solving for $n_{0}^{\prime} S_{0}$ and totally differentiating, we have

$$
\begin{aligned}
d n^{\prime}= & \left(d A-F_{T} d e^{-r T}\right. \\
& \left.-e^{-r T} d F+d Z-n_{0}^{\prime} d S\right) / S_{0}
\end{aligned}
$$

The changes in the holding shares are derived from changes in the value of total assets $(d A)$, changes in the value of discount rate $\left(d e^{-r T}\right)$, changes in the floor $(d F)$, changes in the self-financial factor $(d Z)$, and changes in the stock price $(d S)$.

\section{A comparison of the holding shares between the EADF and the fixed floor disciplines under the CPPI strategy}

To demonstrate the impact of the floor discipline on the changes in the value of the total asset, we conduct a comparison of the holding shares between the EADF and the fixed floor disciplines.

\section{The changes in the holding shares between two adjacent periods under the fixed floor discipline}

Under the fixed floor discipline, the change in the floor is equal to $0, d F=0$. Substituting $d F=0$ into the total differential of the initial value of the stock $\left(d n=\left(m d A-m d F-n_{0} d S\right) / S_{0}\right)$ yields the following expression for the changes in the holding shares $(d n)$ between $t=1$ and $t=0$ :

$$
d n=\left(m d A-n_{0} d S\right) / S_{0} .
$$

\section{The changes in the holding shares between two adjacent periods under the EADF floor discipline}

As the adjustments are contingent on whether the stock price goes up or down, leaving aside the case of the stock price going up, we introduce the changes in the holding shares between two adjacent periods with respect to the stock price going down. When the stock price goes down and triggers a rebalance, an adjustment of the floor is conducted. The new floor becomes $F_{1}=F_{0}+\gamma$, that is, $d F=\gamma$. Substituting $d F=\gamma$ into the total differential of the initial value of the stock $(d n=(m d A-m d F$ $\left.-n_{0} d S\right) / S_{0}$ ) yields changes in the holding shares $\left(d n^{\prime}\right)$ between $t=1$ and $t=0$. That is, we have

$$
d n^{\prime}=\left(m d A-m \gamma-n_{0} d S\right) / S_{0} .
$$

\section{A comparison of the changes in the holding shares between the EADF and the fixed floor disciplines}

When the stock price goes down, subtracting equation (A9) from equation (A10) yields

$$
d n^{\prime}-d n=m(-\gamma) / S_{0} .
$$


The value of the right hand side of equation (A11) is less than 0. Therefore, we have $d n^{\prime}<d n$. That is, when the stock price goes down, the EADF discipline creates less holding shares. As a result, this will increase more downside protection.

\section{A comparison of holding shares between the EADF and the fixed floor disciplines under the SP strategy}

The changes in the holding shares between two adjacent periods under the fixed floor discipline

Let $F_{1}^{T}$ be the floor of $t=1$ and $F_{0}^{T}$ be the floor of $t=0$. As $n_{0}^{\prime}$ is equal to $n_{0} N\left(d_{1}\right)_{0}$, equation (A8) can be rewritten as follows:

$$
\begin{aligned}
d n= & {\left[d A-F_{0}^{T} d e^{-r T}-e^{-r T} d F+d Z\right.} \\
& \left.-n_{0} N\left(d_{1}\right)_{0} d S-n_{0} d N\left(d_{1}\right) S_{0}\right] / N\left(d_{1}\right)_{0} S_{0}
\end{aligned}
$$

Under the fixed floor discipline, the floor is a constant, that is, $d F=0$. Thus, substituting $d F=0$ into equation (A12) yields the changes in the holding shares between $t=1$ and $t=0$ :

$$
\begin{aligned}
d n=[d A & -F_{0}^{T} d e^{-r T}+d Z-n_{0} N\left(d_{1}\right)_{0} d S \\
& \left.-n_{0} d N\left(d_{1}\right) S_{0}\right] / N\left(d_{1}\right)_{0} S_{0}
\end{aligned}
$$

The changes in the holding shares between two adjacent periods under the EADF floor discipline

Similarly, we introduce the changes in the holding shares between two adjacent periods with respect to the stock price decreasing. When the stock price goes down, the floor at $t=1$ is $F_{1}^{T}=F_{0}^{T}+\gamma$, that is, $d F=\gamma$. Substituting $d F=\gamma$ into equation (A12) yields the changes in the holding shares between two adjacent periods:

$$
\begin{aligned}
d n^{\prime}= & \left(d A-F_{0}^{T} d e^{-r T}-\gamma e^{-r T}\right. \\
& +d Z-n_{0} N\left(d_{1}\right)_{0} d S \\
& \left.-n_{0} d N\left(d_{1}\right) S_{0}\right) / N\left(d_{1}\right)_{0} S_{0}
\end{aligned}
$$

A comparison of the changes in the holding shares between the EADF and the fixed floor disciplines

When the stock price goes down, subtracting equation (A13) from equation (A14) yields

$$
d n^{\prime}-d n=-\gamma e^{-r T} / N\left(d_{1}\right)_{0} S_{0}
$$

Thus, we have $d n^{\prime}<d n$. That is, when the stock price goes down, the EADF discipline produces less holding shares. As a result, this will increase more downside protection. 